\title{
La "guerra" es contra nuestras limitaciones conceptuales que el virus ha desnudado
}

\author{
The real war is against our conceptual limitations that the virus has uncovered
}

Heinner Guio ${ }^{\text {1,a }}$, Raúl Ortega ${ }^{2, b}$

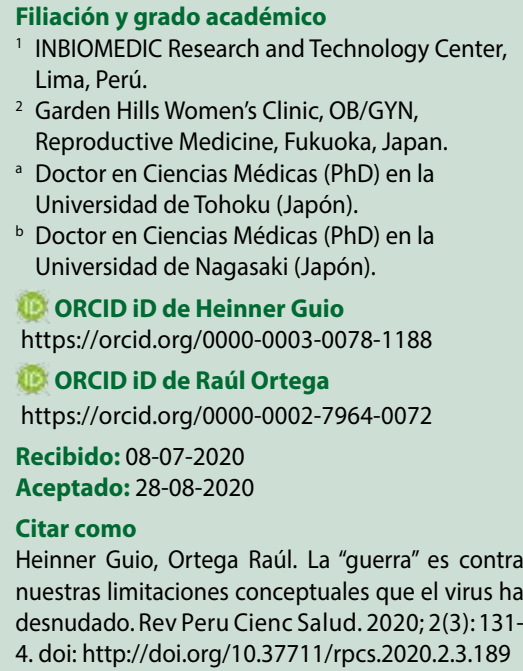

Garden Hills Women's Clinic, OB/GYN,

Reproductive Medicine, Fukuoka, Japan.

Doctor en Ciencias Médicas (PhD) en la

Universidad de Tohoku (Japón).

Doctor en Ciencias Médicas (PhD) en la

Universidad de Nagasaki (Japón).

(iv) ORCID iD de Heinner Guio

https://orcid.org/0000-0003-0078-1188

10. ORCID iD de Raúl Ortega

https://orcid.org/0000-0002-7964-0072

Recibido: 08-07-2020

Aceptado: 28-08-2020

Citar como

Heinner Guio, Ortega Raúl. La "guerra" es contra nuestras limitaciones conceptuales que el virus ha desnudado. Rev Peru Cienc Salud. 2020; 2(3): 131 4. doi: http://doi.org/10.37711/rpcs.2020.2.3.189

La infección por el virus SARS-CoV-2 que nos tiene en medio de una pandemia que cambió el curso de la humanidad, no solo afectó y consumió la vida de muchos pacientes, sino que también se encargó de destruir y quitar la vida principalmente a los responsables de defenderla: personal médico, de enfermería y salud en general. Cuando nos formamos en la escuela de medicina, lo hicimos por convicción y pensando siempre en proteger la salud y la vida de los demás, pero nunca lo hicimos pensando en sacrificar nuestra propia vida. Esta pandemia nos ha demostrado que, a pesar de los grandes adelantos en medicina, la era de los antibióticos, la biología molecular, la capacidad de crear vida en el laboratorio, los billones de dólares gastados en tecnología médica y la inmensa cantidad de tinta empleada en publicar artículos en revistas de ciencias médicas, aún no estamos preparados para enfrentar a un virus nuevo e invisible al ojo humano, pero que ya acabó con la vida de más gente que en las dos bombas atómicas de Hiroshima y Nagasaki.

La opinión pública mundial, rápidamente ha catalogado de"héroes" al personal de salud que enfrenta la COVID-19; una distinción que honra a muchas profesiones ligadas a la salud. Pero, si por un instante tuviésemos la oportunidad de preguntar a aquel médico en su lecho de muerte si desea ser recordado como un "héroe", lo más probable es que diga que "no", que prefiere vivir para cuidar de su familia. La vulnerabilidad en equipos de protección personal, disposición de oxígeno y una mejor infraestructura en salud no estuvieron a nuestro favor, pero ya es muy tarde y la muerte de tantos "héroes" es tal vez, la confirmación del Juramento Hipocrático y la oportunidad única que la vida nos dio para poner a prueba nuestra vocación y conocimiento. Es, como dice mi hijo menor cuando está frente a un reto: "ahí te quiero ver, ahí te quiero ver".

Se menciona que estamos en una "guerra" en la que el enemigo es invisible, una "guerra" que ya cobró un millón de muertes y que, probablemente, llegue a dos millones antes que tengamos acceso a la vacuna. Una "guerra" cruel e inhumana que ha dejado millones de familias desoladas, una "guerra" que no distingue entre grupos étnicos o clases sociales, una "guerra" que además cambió nuestro concepto de las relaciones sociales, y donde un beso puede matar a un ser querido.

El coronavirus es una partícula biológica que carece de reproducción propia y que necesita ingresar a una célula humana para replicarse. Un virus RNA como el SARS-CoV-2 tiene sus propios mecanismos de replicación, de información genética, los cuales se activan al ingresar a la célula (1). Si vulneramos las medidas sanitarias tan básicas y simples como el distanciamiento social, ventilación de las áreas de convivencia, lavado de manos y uso de mascarilla, le damos al virus la oportunidad de que ingrese a nuestro organismo (infección), se replique e infecte otras células, permitiendo así el desarrollo de la 
COVID-19 (enfermedad); la cual llevará al desarrollo de síntomas tan leves como los de un resfrió común, hasta un síndrome de insuficiencia respiratoria aguda grave (SARS, por sus siglas en inglés) de riesgo mortal. Todo esto permite la generación de altas cantidades del virus del SARS-CoV-2 (carga viral), que se eliminan por la nariz, la boca y secreciones del paciente, e infectan a otras personas.

Como vemos hasta aquí y respetando profundamente el dolor por la pérdida de un ser querido o las secuelas de la COVID-19 en la humanidad, nos permitimos preguntar: ¿"qué culpa tiene el virus" ? si, a pesar de las disposiciones del gobierno, no se cumplen las medidas de higiene y aislamiento; de haber llegado al Perú mediante viajeros que a pesar de conocer la pandemia, se desplazaron a lugares de alta infección y no tomaron la precaución debida; si cuando te dicen que mantengas el distanciamiento social no lo haces, evades responsabilidades y, más aún, lo subestimas; si no entendimos ni tomamos conciencia que la reincorporación social, laboral, académica y familiar debe ser un proceso paulatino y que después del levantamiento del aislamiento social, lo primero que hicimos fue correr a abrazar a los seres queridos o amigos de la tercera edad, con una respuesta inmune disminuida, propia de la edad ${ }^{(2,3)} y$, desde entonces, algunos de ellos están con los días contados o, simplemente, ya dejaron de contarlos. Por lo anterior, nos permitimos responder: "¡el virus NO tiene la culpa de nada!"; si hasta carece de reproducción propia como lo mencionamos. Entonces, ¿ante quién estamos librando esta "guerra"?, ¿ante el virus o ante la actitud de las personas que no toman conciencia de lo que estamos viviendo y lo que se vendrá en los próximos meses?

La especie humana afronta una pandemia sin precedentes, solo comparable a la pandemia de gripe española de 1918 que cobró 50 millones de vidas ${ }^{(4)}$. Los gobiernos y organizaciones internacionales de salud hacen sus mejores esfuerzos para contener la morbilidad y mortalidad. Los países que invirtieron y vieron a la investigación científica como una poderosa herramienta de desarrollo, están liderando la generación de nuevos métodos de diagnóstico, vacunas y conocimiento que nos permitan entender al SARS-CoV-2 en términos de infección, enfermedad, trasmisión y protección, entre otros ${ }^{(5)}$.

La respuesta inmune del ser humano es la que, finalmente, controlará la primera o futuras infecciones; sin embargo, el SARS-CoV-2 ha mostrado patrones distintos de generación y sostenibilidad de anticuerpos, lo cual ha motivado a reevaluar las indicaciones de métodos de diagnóstico y monitoreo de la enfermedad ${ }^{(6)}$. Al inicio de la epidemia se sabía que la respuesta inmunológica clásica de anticuerpos
lgM (del día 1 al día 14 de la infección) e lgG (del día 6 hasta algunos años después), eran los conceptos que nos indicaban cómo monitorizar el periodo de infectividad $y$, en base a ello, desarrollar las pruebas serológicas inmunocromatográficas rápidas; implementándose como medidas de reincorporación laboral o control epidemiológico ${ }^{(7)}$. Sin embargo, los estudios nos indicaron su mayor utilidad después del día 7 de infección ${ }^{(8)}$; por lo cual, hoy sabemos que la presencia de lgM pudiera prolongarse y la IgG empezar a disminuir a partir del tercer mes ${ }^{(9)}$. La epidemia previa en el 2003 al SARS-CoV mostró la persistencia de $\operatorname{lgM}$ e IgG hasta 13 semanas posinfección, sugiriendo una respuesta inmune humoral contra el SARS ${ }^{(10)}$. Asimismo, se sabe que los anticuerpos de otros tipos de coronavirus van disminuyendo con el tiempo y han durado entre 12 y 52 meses ${ }^{(11)}$. Por consiguiente, ante estos hallazgos, la utilidad de las pruebas inmunocromatográficas (llamadas comúnmente "pruebas rápidas") sería limitada solamente para evaluar el antecedente de infecciones anteriores. Hasta la fecha, no existe ningún resultado concluyente que revele con certeza el tiempo, concentración y factores asociados a la generación y permanencia de anticuerpos en niños, adultos y adultos mayores.

Los métodos de diagnóstico en la actualidad son las pruebas moleculares basadas en la reacción en cadena de la polimerasa con transcriptasa inversa (RT-PCR), donde los ciclos de amplificación (Cycles threshold: $\mathrm{Ct}$ ) son inversamente proporcionales a la carga viral. Los resultados de un paciente con RT-PCR (+) y con un $\mathrm{Ct}$ de 20 ciclos estaría con una carga viral más alta que un paciente con RT-PCR (+) con un Ct de 30. El concepto de Ct aunado a la información clínica sería de mucha utilidad para la evaluación y seguimiento de los pacientes que han desarrollado la enfermedad; como también sería una herramienta para desarrollar y comparar nuevos métodos moleculares capaces de detectar menores o iguales niveles de carga viral. La creación de un "repositorio COVID" de muestras biológicas ayudaría mucho para la validación de nuevos métodos moleculares más asequibles, técnica y económicamente ${ }^{(12)}$.

El distanciamiento social, lavado de manos y uso de mascarilla, limitan o disminuyen la concentración de partículas virales que pudieran ingresar a nuestro organismo ${ }^{(13)}$; esto explicaría el aumento de casos leves o asintomáticos infectados por coronavirus. La menor concentración de virus inoculado dará más tiempo a nuestro sistema inmunológico a desarrollar una respuesta más adaptativa traducida en concentraciones detectables de lgG similares al efecto de una vacuna atenuada. Sin embargo, es discutible si esta respuesta nos protegería de futuras infecciones, ya que estudios previos han demostrado menor $y$ 
mayor severidad en los pocos casos reportados de reinfección ${ }^{(14)}$. Estas variables debieran ser tomadas en cuenta, durante la evaluación de la inmunidad generada por las vacunas que actualmente están en estudio.

Las manifestaciones clínicas causadas por el SARSCoV-2 varían desde una forma asintomática hasta la progresión de insuficiencia respiratoria. Al inicio de la pandemia se atribuía como factores de riesgo a las personas de la tercera edad, del género masculino o presencia de comorbilidades. Sin embargo, la presencia de estos factores no explicaría del todo la relación entre el factor de riesgo y la severidad de la enfermedad. Recientes estudios genómicos en pacientes con enfermedad severa han establecido, sin embargo, una relación entre la severidad de la enfermedad y los polimorfismos (variaciones en la secuencia de un gen) asociados al cromosoma $3^{(15)}$ y al grupo sanguíneo $\mathrm{A}^{(16)}$.

El $30 \%$ de la población peruana vive sobre los 2500 ms.n.m. y el $60 \%$ de las poblaciones amazónicas están infectadas con algún tipo de parasitosis. Estas condiciones medioambientales y sanitarias no son las condiciones en las que ha sido estudiado y se han establecido los parámetros conceptuales en la inmunología del ser humano. Por consiguiente, ¿la cuantificación de citoquinas o anticuerpos debieran ser extrapolables entre poblaciones medioambientales y sanitarias distintas? Adicionalmente la población latinoamericana está subrepresentada en datos genómicos; por consiguiente, los hallazgos de estudios en una población distante a la nuestra (europea, asiática o africana) como la identificación de nuevas variantes genéticas asociadas a enfermedades trasmisibles y no trasmisibles tendrían que ser validadas en nuestro contexto.

Las investigaciones locales son importantes para sustentar regulaciones y líneas de tratamiento en un país. Después de 7 meses del reporte del primer caso en Perú y haber utilizado diferentes tratamientos, un reciente estudio en 5683 pacientes ha mostrado que no existe un efecto beneficioso en el uso de ivermectina, azitromicina, hidroxicloroquina o sus combinaciones para el tratamiento de pacientes hospitalizados con diagnóstico de la COVID-19 (17). Cerca del $80 \%$ de investigaciones en Perú están, además, centralizada en Lima.

Ningún país estuvo preparado para afrontar la epidemia actual. La agenda de salud pública, de las entidades académicas y del gobierno central para establecer investigaciones en las nuevas generaciones que nos ayuden a entender la fisiología, genética e inmunología de nuestras poblaciones nativas y del poblador peruano siguen sin ser una prioridad. Así mismo, la atención de enfermedades emergentes y reemergentes podrían predecir una futura epidemia, priorizando las inversiones en los sistemas de salud, ciencia y tecnología. $Y$ unas y otras reformas podrían coadyuvar, a su vez, a solventar nuestras limitaciones conceptuales que el virus SARS-Cov-2 ha desnudado.

\section{REFERENCIAS BIBLIOGRÁFICAS}

1. Li X, Geng M, Peng Y, Meng L, Lu S. Molecular immune pathogenesis and diagnosis of COVID-19. Journal of Pharmaceutical Analysis [Internet] 2020; 10(2): 102-8 [Consultado 2020 Sep 29] Disponible en: https://www.sciencedirect.com/science/article/pii/ S2095177920302045

2. Chen J, Kelley WJ, Goldstein DR. Role of Aging and the Immune Response to Respiratory Viral Infections: Potential Implications for COVID-19. J Immunol [Internet] $2020 \mathrm{Jul}$ 15; 205(2): 313-20 [Consultado 2020 Sep 29] Disponoble en: https://pubmed.ncbi.nlm.nih. gov/32493812/

3. Nikolich-Zugich J, Knox KS, Rios CT, Natt B, Bhattacharya D, Fain MJ. SARS-CoV-2 and COVID-19 in older adults: what we may expect regarding pathogenesis, immune responses, and outcomes. GeroScience. Springer [Internet] 2020 Apr; 42(2): 505-514 [Consultado 2020 Sep 29] Disponible en: https://www.ncbi.nlm.nih.gov/ pmc/articles/PMC7145538/

4. Taubenberger JK, Morens DM. 1918 Influenza: the Mother of All Pandemics. Emerg Infect Dis [Internet] 2006 Jan; 12(1): 15-22 [Consultado 2020 Oct 1] Available from: https://www.ncbi.nlm.nih.gov/pmc/articles/ PMC3291398/

5. Yesudhas D, Srivastava A, Gromiha MM. COVID-19 outbreak: history, mechanism, transmission, structural studies and therapeutics. Infection. Springer [Internet] 2020 Sep 4 [Consultado 2020 Sep 30] Disponible en: https://doi.org/10.1007/s15010-020-01516-2

6. Sette A, Crotty S. Pre-existing immunity to SARS-CoV-2: the knowns and unknowns. Nature Reviews Immunology [Internet] 2020 Aug; 20(8): 457-458 [Consultado 2020 Sep 29] doi: 10.1038/s41577-020-0389-z

7. Ministerio de Salud. Perú. Instructivo para la aplicación de las pruebas rápidas [Internet] [Consultado 2020 Sep 30] Disponible en: https://web.ins.gob.pe/es/saludpublica/como-hacer-prueba-rapida

8. Zhao J, Yuan Q, Wang H, Liu W, Liao X, Su Y, et al. Antibody responses to SARS-CoV-2 in patients of novel coronavirus disease 2019. Clin Infect Dis [Internet] 2020 Mar 28 [Consultado 2020 Sep 29] Disponible en: https:// pubmed.ncbi.nlm.nih.gov/32221519/

9. Chen $Y$, Tong $X, \mathrm{Li} Y, \mathrm{Gu} B$, Yan J, Liu $Y$, et al. A comprehensive, longitudinal analysis of humoral responses specific to four recombinant antigens of SARS-CoV-2 in severe and non-severe COVID-19 patients. PLoS Pathog [Internet] 2020 Sep 1; 16(9): e1008796 [Consultado 2020 Sep 29] Disponible en: https://pubmed.ncbi.nlm.nih.gov/32913364/

10. Zhu M. SARS Immunity and Vaccination. Cellular \& Molecular Immunology [Internet] 2004 Jun; 1(3): 193198 [Consultado 2020 Sep 29] Disponible en: http:// www.cmi.ustc.edu.cn/1/3/193.pdf

11. Kellam $P$, Barclay W. The dynamics of humoral immune responses following SARS-CoV-2 infection and the 
potential for reinfection The Journal of general virology NLM (Medline) [Internet] 2020; 101(8): 7917 [Consultado 2020 Oct 1] Disponible en: https:// www.microbiologyresearch.org/content/journal/ jgv/10.1099/jgv.0.001439

12. Niedzwiedz CL, O’Donnell CA, Jani BD, Demou E, Ho FK, Celis-Morales C, et al. Ethnic and socioeconomic differences in SARS-CoV-2 infection: Prospective cohort study using UK Biobank. BMC Med [Internet] 2020 May 29; 18(1): 160 [Consultado 2020 Sep 29] doi: 10.1186/ s12916-020-01640-8

13. Gandhi M, Rutherford GW. Facial Masking for Covid-19 - Potential for "Variolation" as We Await a Vaccine. N Engl J Med [Internet] 2020 Sep 8 [Consultado 2020 Sep 29] doi: 10.1056/NEJMp2026913

14. Tomassini S, Kotecha D, Bird PW, Folwell A, Biju S, Tang JW. Setting the criteria for SARS-CoV-2 reinfection six possible cases. Journal of Infection. W.B. Saunders Ltd [Internet] 2020 Aug 12; S0163-4453(20)30546-6 [Consultado 2020 Sep 29] doi: 10.1016/j.jinf.2020.08.011
15. Zeberg $H$, Pääbo $S$. The major genetic risk factor for severe COVID-19 is inherited from Neanderthals. Nature [Internet] 2020 Sep 30 [Consultado 2020 Oct 1] Disponible en: http://www.nature.com/articles/s41586020-2818-3

16. Ellinghaus $D$, Degenhardt $F$, Bujanda $L$, Buti $M$, Albillos A, Invernizzi $P$, et al. Genomewide Association Study of Severe Covid-19 with Respiratory Failure. N Engl J Med [Internet] 2020 Jun 17 [Consultado 2020 Oct 1] Disponible en: http://www.nejm.org/doi/10.1056/ NEJMoa2020283

17. Soto-Becerra P, Culquichicón C, Hurtado-Roca $Y$, Araujo-Castillo $\mathrm{R}$ V. Real-World Effectiveness of hydroxychloroquine, azithromycin, and ivermectin among hospitalized COVID-19 patients: Results of a target trial emulation using observational data from a nationwide Healthcare System in Peru. medRxiv [Internet] 2020 Oct 8 [Consultado 2020 Oct 9];2020.10.06.20208066. Disponible en: https://doi. org/10.1101/2020.10.06.20208066 